\title{
Spontaneous amputation of the forearm in a cocaine user case report
}

\begin{abstract}
The menace of cocaine addiction is real and mainly affects young people, the peripheral arterial thrombosis induced by cocaine are rare but they are described in the literature, but never cases of spontaneous amputation. We will describe in this manuscript a rare case of spontaneous amputation of the forearm in 38 years old man, known as a drug addict with notions of cocaine use. He consulted at the emergency for spontaneous loss of his forearm with absolute calm. This takes us to publish this case to discuss the consequences of cocaine use on the health both the vital prognosis than on functional prognosis and its impact on public health.
\end{abstract}

Keywords: spontaneous amputation, cocaine, arterial thrombosis
Volume 2 Issue I - 2018

\author{
Samir Hamoudi, Philbert Ntarataze, Jean \\ François Dumez \\ Orthopedic and Trauma Surgery Unit, hospital Center Moulins- \\ Yzeure, France
}

\begin{abstract}
Correspondence: Samir Hamoudi, Orthopedic and Trauma Surgery Unit, hospital Center Moulins-Yzeure, France, Tel 0033628I23837, Email samirhamoudi@gmail.com
\end{abstract}

Received: January 09, 2018 | Published: February 06, 2018

\section{Introduction}

The peripheral arterial thrombosis induced by cocaine are rare but described in the literature but never cases of spontaneous amputation were. The mechanism of thrombosis is not fully elucidated, but as a rule, the disease affects small vessels. Talking about spontaneous amputation nowadays seems out of date, as it's almost impossible; yet, it is the case of the 38 years old man, known as a drug addict with notions of cocaine use. Researches in the literature put in evidence that the rare cases of spontaneous amputation published did not involve cocaine. It is about cases published in the medicine, surgery, and pharmacy diary since the $18^{\text {th }}$ century. For example, the case of Dr Vandergracht, surgeon of his time who, in diagnosing a hand and forearm gangrenes during the Lille's epidemic between 1749 and 1750 , preferred to wait before performing the amputation until the mortification was absolutely limited. Also, the case of this young 20 years old man who was victim of a ballistic trauma in 1839. His parents and he refused any treatment choosing to let nature run wild, but few weeks after her leg got separated from femur. Other cases were described following frostbite, putrid fever, typhus ${ }^{1-3}$ Ischemia induced by tourniquet mustn't be forgotten, but in the literature, the published cases involve accidental tourniquet's omission at the limb's root in the finger surgery. ${ }^{4}$

\section{Clinical case}

Mr M.E., 38 years old, right-handed, unemployed, known as a drug addict using cocaine by injection, on treatment but poorly monitored. In his background in addition to various infectious episodes, there is essentially this notion of confusion with dysphasia but investigations have not been pushed, was it a transient stroke? He consulted at the emergency for spontaneous loss of his forearm (Figure 1). The patient said it began few months ago when necrotic areas started to appear on his forearm. Each time he consulted a doctor, an antibiotic treatment was prescribed but no improvement was noticed. Worse, neurological disorders started to manifest on his hand with a sphacelus aspect which kept on increasing. For him, that was what motivated him to check it again. A topical antibiotic treatment was prescribed. Noted that the patient's discourse was inconsistent and seem absurd. Letting things evolve, the eve of his emergency department visit, wanting to wash, his forearm broke away making surgical disarticulation at his elbow. On examination we were amazed by the calm of the patient who arrived with his forearm which looked like mummified in a bag. The spontaneous amputation was done at the elbow joint with exposure of the distal hummers (Figure 2). The x-ray examination did not show signs of osteitis (Figure 3). After assessment, the patient was taken to the operating room where we conducted further amputation stump with regularization (Figure 4).

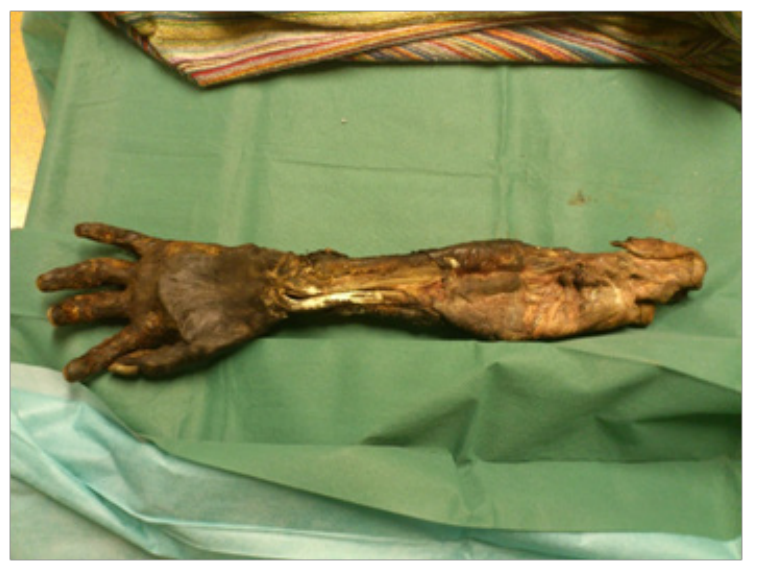

Figure I Forearm amputated and mummified.

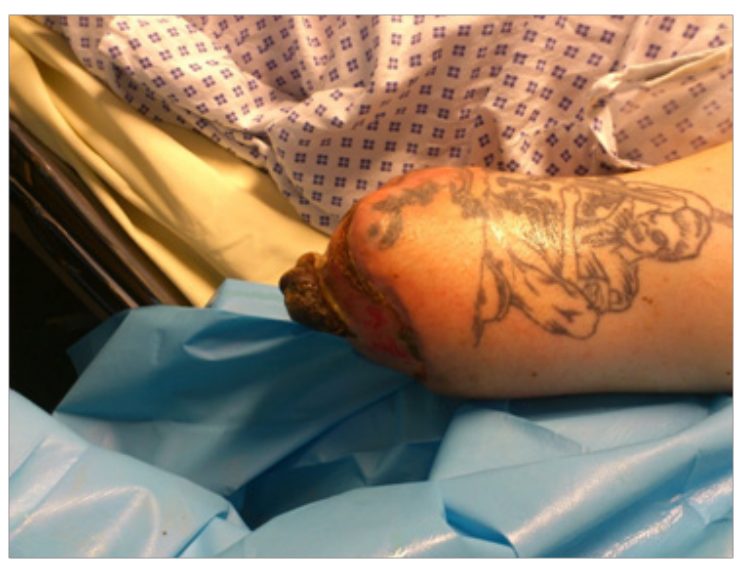

Figure 2 disarticulation of the elbow joint with exposure of the distal hummers. 


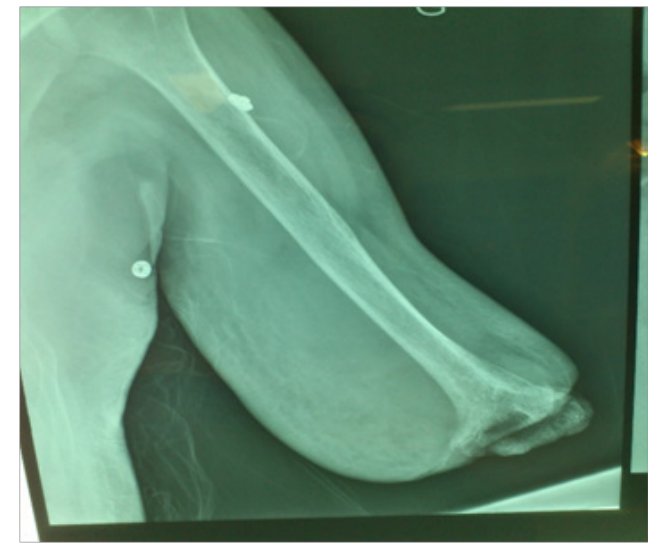

Figure 3 X-ray examination.

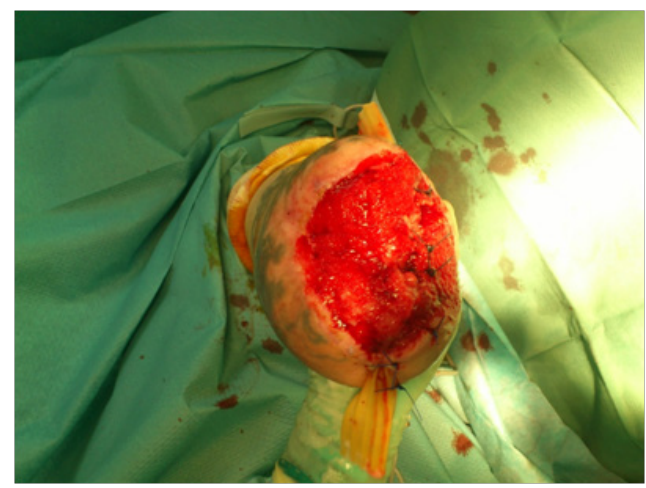

Figure 4 Amputation stump after regularization.

\section{Discussion}

This case shows that, apart from overdoses, drugs can cause devastating toll with low noise evolution, this is the proof. A spontaneous amputation should no longer exist today, and except in certain cases published in the literature, I was not thinking I should be faced to it one day. This brings us to discuss some key points:

I. Drug's effect on public health

II. The diagnostic care and support to this type of patients.

III. The young age of these patients.

Comparative cadaveric studies among subjects with cocaine use history and subjects with traumatic death show that a fairly large percentage of subjects in the first group have cardiovascular lesions. ${ }^{5}$ Other studies show the relationship between the abuse of cocaine and acute arterial thrombosis ${ }^{6,7}$ while another one suggests that some vascular injuries in the aftermath of the cocaine use, are due to vasospasm of the big arteries and thrombosis is secondary. Several articles insist on the fact that arterial thrombosis cocaine induced should be suspected in front of any patient suffering from acute ischemia without cardiovascular risk factors and a cocaine use history. ${ }^{9-11}$ The consumption of tobacco and alcohol are considered as aggravating factors and are noted in this patient, but on the other hand no drug intake apart from the topicals prescribed in local application, it is an aggravating substance of the vascular effect of cocaine including Econazole, Erythromycin or other products that the patient does not remember. ${ }^{12}$ In our patient case, who have no cardiovascular risk factors but an episode of confusion and dysphasia that can be related to a stroke, ${ }^{13}$ the origin of the ischemia can only be linked to cocaine consumption alone or associated with other aggravating factors but of which there is no evidence in this case, otherwise, the other plausible cause could be that while pricking and under the effect of the product, the patient has left in place the tourniquet which caused the ischemia; especially as the echo Doppler members was normal. Unfortunately, no investigations were done on the amputated limb as it was completely sphaceled.

The discussion will be closed with three questions:

I. Did the patient really consult? If he did, it's a serious mistake to let evolved such gangrene in the 21 st century.

II. How can he let things evolve? This explains the indifference of these patients concerning their health, especially as this man didn't seemed to be worried about his condition.

III. Do regular trainings have to be made to control the drug interaction in this type of patient?

\section{Conclusion}

The complications related to cocaine use are real and threatening as much in terms of public health as in term of economy. The approach of these patients must be cautious before deciding or trivializing the diagnosis, especially if ischemic events started to appear as conducing correct investigations leads to an adequate care which can avoid this type of disaster.

\section{Acknowledgements}

None.

\section{Conflict of interest}

The author declares no conflict of interest.

\section{References}

1. Boucher M. Mémoire sur la gangrène épidémique qui a régné à Lille en Flandre entre 1749 et 1750. Journal de médecine chirurgie et pharmacie. $1762 ; 1: 504-507$.

2. Dezeimeris JE. L'expérience. Journal de Médecine et de Chirurgie. 1839:p. 106-107.

3. Cooper S. Dictionnaires de chirurgie pratique. 1826;540 p.

4. Mallard F, Saint Cast Y, Richou J, et al. Long-term functional outcomes of digital ischemia under tourniquet: observations in three cases. Chir Main. 2012;31(6):358-363.

5. Simpson RW, Edwards WD. Pathogenesis of cocaine-induced ischemic heart disease. Autopsy findings in a 21-year-old man. Archive of Pathology and Laboratory Medecine. 1986;110(6):479-484.

6. Lange RA, Hillis LD. Cardiovascular Complications of Cocaine Use. $N$ Engl J Med. 2001;45(5):351-358.

7. Syed FF, Beeching NJ. Lower-limb deep-vein thrombosis in a general hospital: risk factors, outcomes and the contribution of intravenous drug use. QJM An International Journal of Medicine. 2005;98(2):139-145.

8. Hantson P. Complications neurovasculaires aiguës liées à la consommation de la cocaïne, des amphétamines et du cannabis. Réanimation. 2010 ;19(6):533-538.

9. Zhou W, Lin PH, Bush RL, et al. Acute arterial thrombosis associated with cocaine abuse. J Vasc Surg. 2004;40(2):291-295. 
10. Mirzayan R, Hanks SE, Weaver FA. Cocaine-induced thrombosis of common iliac and popliteal arteries. Annals of Vascular Surgery. 1998;12(5):476-481.

11. Collins CG, Seoighe D, Ireland A, et al. Cocaine-associated lower limb ischemia. Vascular. 2008;16(5):297-299.
12. Gallelli L, Gratteri S, Siniscalchi A, et al. Drug-Drug Interactions in cocaine-users and their clinical implications. Curr Drug Abuse Rev. 2017:20.

13. Siniscalchi A, Bonci A, Mercuri NB, et al. Cocaine dependence and stroke: pathogenesis and management. Curr Neurovasc Res. $2015 ; 12(2): 163-172$ 